\title{
A educação em fluxo ou a morte do tempo do ócio
}

\author{
Eric de Carvalho
}

Resumo: O tráfico intenso de veículos de vias térreas na cidade de São Paulo é um fator decisivo para as decisões que envolvem deslocamento urbano. A escolha pelo local de residência, trabalho, lazer, alimentação e mesmo educação envolve um planejamento sobre o tempo que deve ser dispendido durante os deslocamentos entre os locais de práticas dessas atividades. O processo de midiatização da educação tendo como principal estratégia o acesso a ferramentas de Educação à Distância por meio de suportes tecnológicos portáteis tem estimulado que o paulistano estude durante seu tempo de deslocamento na cidade. Este artigo analisa esse processo sob a perspectiva nórdica das teorias de midiatização, utilizando entrevistas em profundidade com usuários dessa modalidade educacional que relatam como essa tecnicidade permite a organização de seu tempo na cidade.

Palavras-Chave: Midiatização. Educação à distância. Tempo. Ócio. Comunicação.

\section{Education in flow or death of leisure time}

Abstract: Intense traffic of land vehicles in São Paulo city is a decisive factor for decisions that include urban displacement. Choosing on residence, work, entertainment, supply and even education locations involves planning on time spending in displacement among these places. Education mediatization process based on use of main strategy of the access to E-learning tools throughout portable technological devices stimulates Sao Paulo's citizens to study during their travelling time on the city turning his leisure time on working time. This article analyses this process on Nordic perspective of mediatization theories and makes interviews with E-learning users that describe the way this technicity allows organization of their time on city.

Keywords: Mediatization. E-learning. Time. Leisure. Communication. 


\section{Introdução}

A questão da educação em uma metrópole como São Paulo sofre influência direta de diversas mediações que interferem no desempenho dessa prática. Dentre esses fatores, a questão geográfica, mais especificamente o intenso tráfego de veículos de vias térreas pela cidade, se torna imperativo na definição de locais para a prática dessa atividade. Dessa forma, o paulistano planeja seu cotidiano tendo em vista os deslocamentos que precisará realizar no período de um dia útil, contemplando uma equação entre tempo de deslocamento e distâncias que lhe permita exercer todas suas atividades planejadas para o dia. Frequentemente essas atividades incluem um deslocamento de casa para o local de trabalho e deste para um local de estudo antes do retorno para casa. Como nem todo paulistano consegue que seus locais dessas práticas fiquem próximos um ao outro, constantemente esses deslocamentos podem levar muito tempo, tomando entre 2 até 5 horas de um dia. Em uma cidade com um tráfego tão intenso, grandes distâncias podem se tornar impeditivas para a frequência em uma instituição de ensino. Esse cenário é favorável para o crescimento da prática da modalidade do ensino à distância.

O ensino a distância $(\mathrm{EaD})$ é uma prática baseada no acesso de alunos a material didático sem a mediação presencial de um professor. No Brasil, existe há cerca de quatro décadas, sendo inicialmente baseada no sistema de envio de apostilas e material de apoio para alunos que estudavam, enviavam seus cadernos de exercícios de volta para a sede da instituição e eram avaliados; de toda forma, a modalidade ganhou grande projeção após o advento da internet, que permitiu uma maior produção e divulgação desse material didático, assim como o surgimento de grandes instituições que desenvolveram o mercado de $\mathrm{EaD}$, divulgando a técnica em larga escala e colaborando para a promoção de um processo de midiatização da educação.

Analisaremos a midiatização da educação partindo da observação das mediações que envolvem o processo comunicacional na educação até as mudanças que ocorreram nos processos educacionais, após o aperfeiçoamento das tecnicidades que estruturam a modalidade do EaD.

Como todo processo comunicacional, a comunicação na educação é permeada por mediações que influenciam o próprio estabelecimento de interações entre os agentes envolvidos. Martín-Barbero (2010) estabeleceu um mapa de mediações (Fig. 1), para analisar a relação entre forças das lógicas da produção/competências da recepção e formatos industriais/matrizes culturais da comunicação. 
Figura 1 - Diagrama metodológico das mediações

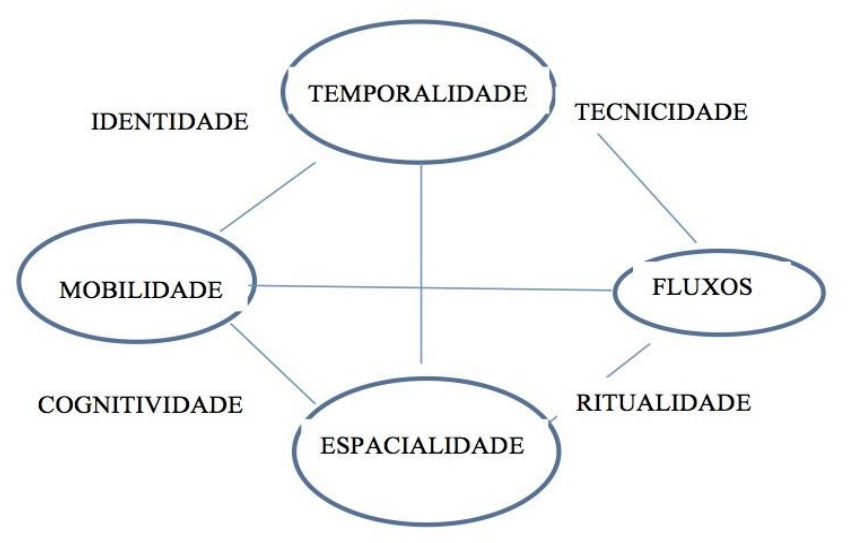

Fonte: Reprodução do diagrama metodológico das mediações que consta em Lopes (2014, p. 73).

Esse diagrama articula mediações comunicativas da cultura, presentes nos processos comunicacionais do cotidiano, como as mediações presentes nas relações temporalidade/espacialidade e mobilidade/fluxos. A proposta de um estudo focado nas mediações culturais advém de um olhar epistemológico, que reconhece a mídia como local de reprodução de comportamentos e formatação da cultura contemporânea e não apenas como suporte técnico para divulgação de mensagens. O olhar, proposto por Martín-Barbero (2010), articula o estudo de comunicação com estudos de cultura, confrontando as representações de grupos sociais, conforme produzidos pela mídia com as recepções desses grupos por meio da fruição da mensagem; sob essa perspectiva, a experiência estética do receptor é tornada produção poética de sentido.

Retomando as mediações presentes nas relações temporalidade/espacialidade e mobilidade/fluxos. O eixo espaço-temporal refere-se à percepção de mudança nesses conceitos, a uma suposta compressão espaço-temporal após o uso da internet: no que tange à temporalidade, a sensação de urgência, mais acontecimentos em menos tempo, culto ao presente em detrimento à historicidade; no que se refere à espacialidade, a sensação de proximidade de tudo, mesmo à distância, a relação da presença em espaços físicos e digitais e a apropriação desses espaços. O conceito de mobilidade refere-se ao deslocamento de pessoas pelas espacialidades, êxodos, migrações e navegabilidade em espaços físicos e digitais, enquanto o conceito de fluxos se refere a fluxos informacionais, textuais, imagéticos.

Como dito anteriormente, a modalidade presencial da educação na cidade de São Paulo é bastante influenciada pela mediação da mobilidade, pois grandes distâncias percorridas por 
longos períodos de tempo podem impossibilitar a disponibilidade necessária ao estudo presencial em uma instituição de ensino. Esse cenário prejudica a adesão ao ensino presencial, mas encontra no EaD, modalidade estabelecida sob determinadas tecnicidades, a possibilidade de um ensino mediado pelo fluxo de informações, por meio de aparatos tecnológicos, como aparelhos celulares, ou tablets.

O uso dessas tecnicidades permite uma reapropriação das relações com as temporalidades e espacialidades. O tempo de deslocamento pela cidade torna-se um potencial momento de aprendizado. Ou ainda, a construção discursiva de cursos que ofertam a modalidade de EaD utiliza o argumento de que o deslocamento por um espaço em determinado tempo, que compreendia um "desperdício" pelo aspecto de mobilidade tornou-se um tempo "ganho" para aprendizado pela perspectiva do fluxo de informações. As noções de “desperdício" e "ganho" de tempo são discursos publicitários que revelam a supervalorização do tempo ocupado com atividades consideradas produtivas em relação a tempos de ócio, valores exaltados pela sociedade a partir da velocidade do fluxo de informações obtidas desde a expansão da internet. Nessa perspectiva, a mediação da tecnicidade adquire relevância, influenciando na percepção de temporalidades e espacialidades e impactando nas ritualidades do cidadão no processo comunicativo.

Assim, apesar de a comunicação no campo da educação ser passível de análise pela perspectiva das mediações comunicativas da cultura, a ascendência da mediação da tecnicidade na prática da educação na modalidade $\mathrm{EaD}$, torna mais adequada a observação do fenômeno pela perspectiva da teoria da midiatização.

\title{
A midiatização da educação
}

A perspectiva teórica da midiatização analisa a mudança da relação estrutural entre a mídia e outras esferas da sociedade, que se influenciam por meio de processos comunicacionais que permeiam o cotidiano.

\begin{abstract}
A midiatização diz respeito às transformações estruturais de longa duração na relação entre a mídia e outras esferas sociais. Em contraste à mediação, que lida com o uso da mídia para práticas comunicativas específicas em interação situada, a midiatização preocupa-se com os padrões em transformação de interações sociais e relações entre os vários atores sociais, incluindo os indivíduos e as organizações. Desta perspectiva, a midiatização envolve a institucionalização de novos padrões de interações e relações sociais entre os atores, incluindo a institucionalização de novos padrões de comunicação mediada. (HJARVARD, 2014, p. 24).
\end{abstract}

Para Hjarvard (2014), a teoria de midiatização se aproxima de uma teoria de médio alcance, que não explica qualquer processo comunicacional no mundo e na história, mas se 
estabelece em um contexto sociocultural específico e se aplica a interações sociais especificamente situadas. $\mathrm{O}$ autor enfatiza uma abordagem institucional do conceito de midiatização como um processo que estrutura práticas culturais que assimilam formatos tecnológicos, adotando uma lógica midiática para sua organização.

\begin{abstract}
Ele se concentra nos padrões gerais das práticas dentro de um contexto institucional específico, não numa miríade de variações de interação situada. Ao mesmo tempo, uma abordagem institucional insiste em um embasamento empírico para a generalização e construção de teoria, e, portanto, permanece cética de declarações de escala macro sobre a influência universal da mídia na cultura e na sociedade independentemente do contexto. Como tal, a teoria da midiatização deveria apoiar a construção de teorias de médio alcance, ou seja, propostas que lidam com a influência da mídia dentro de domínios ou subdomínios institucionais particulares (como a política ou o entretenimento infantil) em um dado contexto histórico e sociocultural. (HJARVARD, 2014, p. 27).
\end{abstract}

Segundo Hjarvard (2014), o processo de midiatização impacta sobre as ritualidades referentes à própria prática cultural da instituição midiatizada. Tecnicidades emergentes permitem que atividades exercidas presencialmente passem a ser exercidas por meio de interação com um meio. "A midiatização direta refere-se às situações em que uma atividade antes não-mediada se converte em uma forma mediada, ou seja, a atividade é realizada através da interação com um meio." (HJARVARD, 2012, p. 66).

Essa perspectiva é bastante adequada para a análise da midiatização da educação. A modalidade EaD permite a um aluno ter acesso a determinado conteúdo por meio da mediação de algum aparato tecnológico. Dessa forma, a instituição de ensino produz um conteúdo que será disponibilizado digitalmente para acesso remoto de seus alunos, que estudarão e responderão às atividades propostas, assim como interagirão com a instituição, com uma grande diferença em relação à prática do estudo presencial: poderão fazê-lo em qualquer lugar a qualquer momento, mediante a tecnicidade necessária para tal. Dessa forma, é relevante reforçar que a mediação da tecnicidade proporcionada pelo $\mathrm{EaD}$ pode diminuir a influência das espacialidades e temporalidades no exercício da atividade educacional.

Essa característica fundamental do EaD se converte em um argumento publicitário que enfatiza a possibilidade de estudo "a qualquer hora ou lugar", "ideal para quem não tem tempo para frequentar uma escola ou faculdade”, argumentação comum a produtos alimentícios associados à praticidade, uma educação "ready to $g o^{1}$ ", que se encaixa no cotidiano de um cidadão que vive em constante deslocamento. Esse estudante pode assimilar novos

\footnotetext{
${ }^{1}$ Em tradução livre: pronto para ir. Termo utilizado no marketing para produtos que são comprados e consumidos fora de um estabelecimento comercial, em movimento, como um refrigerante gelado em uma barraca.
} 
conhecimentos e testar seu aprendizado enquanto se desloca pela cidade ao utilizar algum veículo de via térrea. Essa prática reforça os discursos de "otimização do tempo" e "tempo é dinheiro" que permeiam o cotidiano de uma vida na metrópole.

Essa argumentação se fundamenta sobre duas lógicas bastante difundidas na sociedade: a) a dificuldade de deslocamento para acessar um local específico para o exercício do estudo/a não-necessidade de um local específico para essa prática; e b) estudar em deslocamento poupa o tempo do estudante para outras atividades culturais que só podem ser realizadas presencialmente. É uma argumentação publicitária, passível de questionamento. Que atividades só podem ser realizadas presencialmente? Qual a prioridade das atividades para serem realizadas remotamente ou presencialmente? Qual a importância do local da instituição de ensino na aprendizagem? A interação presencial com outros alunos (e com o professor) é importante para a aprendizagem? Mais uma vez é possível mencionar a noção das mediações de Martín-Barbero (2010). Qual a importância das espacialidades e temporalidades no processo de ensino? Como estão presentes no EaD?

Do ponto de vista espacial, o EaD praticado durante o deslocamento na cidade remete à noção de não-lugar, de Marc Augé (2004). "Se um lugar pode se definir como identitário, relacional e histórico, um espaço que não pode se definir nem como identitário, nem como relacional, nem como histórico definirá um não-lugar.” (AUGÉ, 2004, p. 73).

Assim, o estudante de $\mathrm{EaD}$ não aprende em uma instituição de ensino, mas, sim, em outros locais como em sua casa ou, como citado aqui, em deslocamento no trânsito. Dessa forma, se priva de um ambiente planejado para a prática da aprendizagem, com biblioteca, silenciosos espaços de estudo e mesmo a presença de colegas com o mesmo desafio, cujas participações em aula podem estimular a curiosidade e mesmo tirar dúvidas entre os colegas. A alteridade é fundamental para o processo de aprendizado, ou seja, as trocas entre semelhantes (no caso, alunos de uma mesma sala) são estimulantes para a participação em aula e um aprendizado em conjunto. Outros locais onde o EaD pode ser apreendido apresentarão outras condições de estímulos externos que podem atrapalhar o aprendizado do aluno.

Os não-lugares, contudo, são a medida da época: medida quantificável e que se poderia tomar somando, mediante algumas conversões entre superfície, volume e distância, as vias aéreas, ferroviárias, rodoviárias e os domicílios móveis considerados "meios de transporte" (aviões, trens, ônibus), os aeroportos, as estações e as estações aeroespaciais, as grandes cadeias de hotéis, os parques de lazer, e as grandes superfícies da distribuição, a meada complexa, enfim, redes a cabo ou sem fio, que mobilizam o espaço extraterrestre para uma comunicação tão estranha que muitas vezes só põe o indivíduo em contato com outra imagem de si mesmo. (AUGÉ, 2004, p. 74-75). 
A ausência de trocas ocasionada pela eliminação do ambiente de estudo cobra um preço comprometendo, além da troca com o Outro, o tempo da reflexão e contemplação. "O cansaço da sociedade do desempenho é um cansaço solitário, que atua individualizando e isolando" (HAN, 2017, p. 71). Segundo Han (2017), a contemporaneidade caracteriza a sociedade do cansaço, que exalta a velocidade acelerada e o desempenho, em detrimento do pensamento reflexivo.

\begin{abstract}
Os desempenhos culturais da humanidade, dos quais faz parte também a filosofia, devem-se a uma atenção profunda, contemplativa. A cultura pressupõe um ambiente onde seja possível uma atenção profunda. Essa atenção profunda é cada vez mais deslocada por uma forma de atenção bem distinta, a hiperatenção (hyperattention). Essa atenção dispersa se caracteriza por uma rápida mudança de foco entre diversas atividades, fontes informativas e processos. (HAN, 2017, p. 33).
\end{abstract}

A reflexão proposta questiona não apenas um ambiente, mas também um tempo para contemplação. A prática do estudo durante o tempo de deslocamento em um transporte público configura a materialização da cultura da multitarefa e da eliminação do "desperdício" de tempo, mas também promove a morte do tempo do ócio, fundamental para o desenvolvimento de um pensamento criativo.

De Masi (2000) argumenta que o ócio criativo é uma atividade saudável que estimula a reflexão e a criatividade, enquanto que o trabalho intenso permite a produção, mas inibe a inovação. Assim, atividades intelectuais precisam do estímulo do tempo ocioso, do vagar tranquilo e do olhar contemplativo para alimentar a criatividade. Essa filosofia necessita de uma postura contemplativa ao invés da preocupação com a performance típica da sociedade do cansaço.

Assim, a perspectiva institucional de midiatização, segundo Hjarvard (2012), poderia apontar para novos processos de educação, rápidos e independentes de uma localização estática, porém, com desvantagens em relação à ausência de um convívio presencial com colegas e professores e mesmo de um ambiente educacional. Essa perspectiva poderia ser analisada sob outro prisma se considerarmos que nas sociedades contemporâneas que contam com as tecnicidades adequadas, o cidadão já está tão habituado a se relacionar com ambientes digitais que alterou sua relação com a forma de fruição desses materiais didáticos, apreendidos como um consumo midiático de um material produzido e veiculado por redes. Esse olhar pode ser analisado sob a perspectiva da midiatização, segundo Hepp (2014). 


\section{A midiatização do aprendizado}

A perspectiva teórica da midiatização proposta por Hepp (2014) possui uma visada socioconstrutivista voltada às práticas da comunicação cotidiana. A midiatização "enfoca a construção comunicativa em transformação da cultura e da sociedade" (HEPP, 2014, p. 47). Seu olhar aproxima a perspectiva institucionalista de Hjarvard (2012) a uma abordagem cultural, mostrando que a sociedade pode também influenciar as instituições.

O intuito desse tipo de pesquisa é investigar a inter-relação entre a mudança da comunicação midiática e a transformação sociocultural como parte das práticas de comunicação cotidianas, e como a alteração dessas práticas está relacionada à construção da realidade comunicativa em mudança. (HEPP, 2014, p. 49).

A pesquisa sobre midiatização possui como objeto a própria transformação da realidade comunicativa e social. Sob essa perspectiva, a familiaridade dos cidadãos com o consumo midiático de conteúdo, sejam eles formatos sonoros como podcasts, audiovisuais como serviços de streaming ou mesmo textos, incentivou a "migração" dessa tecnicidade do campo do entretenimento para o campo educacional. Organizações passaram a desenvolver cursos de EaD para consumo midiático de seus alunos, porque esses já estão acostumados à fruição de um conteúdo midiatizado, ou seja: nessa perspectiva o hábito cultural inspira a adaptação dos formatos industriais (a demanda latente incentiva a oferta dessa modalidade educacional).

Cabe aqui contextualizar o conceito de consumo midiático, consumo cultural e recepção, a partir das considerações de Toaldo e Jacks (2013), estabelecidas sobre os estudos de Canclini (1993; 2005). O consumo cultural, na perspectiva das mediações culturais, é uma prática de natureza essencialmente simbólica, que se configura como lugar de diferenciação social e distinção simbólica entre os grupos, de modo que Canclini (1993, p. 34), o define como “o conjunto de processos de apropriação e usos de produtos nos quais o valor simbólico prevalece sobre os valores de uso e de troca, ou onde ao menos estes últimos se configuram subordinados à dimensão simbólica".

Sob essa perspectiva, o consumo cultural promove distinção social, ajuda a definir identidades culturais, expressa posicionamentos em relação a questões sociais e políticas. $\mathrm{O}$ consumo midiático pode ser analisado como uma vertente do consumo cultural sob uma das mediações culturais, a mediação técnica-midiática. A fruição de conteúdos veiculados por mídias diversas configura o consumo cultural de um produto midiático (ou de um conteúdo midiatizado), ou seja, um consumo midiático. 
No caso do consumo midiático, trata-se do consumo do que a mídia oferece: nos grandes meios - televisão, rádio, jornal, revista, internet, sites, blogs, celulares, tablets, outdoors, painéis ...- e nos produtos/conteúdos oferecidos por esses meios novelas, filmes, notícias, informações, entretenimentos, relacionamentos, moda, shows, espetáculos, publicidade, entre outros. (TOALDO; JACKS, 2013, p. 6-7).

Enquanto um estudo de recepção se concentra na interpretação de conteúdos de fenômenos midiáticos por seus receptores, o estudo de consumo midiático analisa, não somente a apropriação desses conteúdos, como também a relação com os meios nos quais são veiculados. Esse processo de midiatização de conteúdo torna fenômenos passíveis de consumo cultural em produtos midiáticos passíveis de consumo midiático por receptores.

Dessa forma, o consumo midiático de um conteúdo midiatizado como material didático de $\mathrm{EaD}$ poderia corroborar a perspectiva socioconstrutivista de Hepp (2014), que permite analisar esse fenômeno como uma manifestação cultural que pode ter estimulado instituições de ensino a midiatizar seus processos para seus alunos.

No intuito de analisar a relação entre uma perspectiva institucionalista ou socioconstrutivista da midiatização da educação ou, nesse caso, entre a oferta e demanda por cursos EaD como uma tendência sugerida por instituições ou apontada pela sociedade, foram realizadas algumas entrevistas em profundidade com usuários de curso $\mathrm{EaD}$ residentes na cidade de São Paulo que estudam em seu tempo de deslocamento em meios de transporte pelo espaço urbano. Buscou-se descobrir suas motivações, vantagens e dificuldades na fruição de um material didático midiatizado nas condições e mediações de deslocamento no transporte público. A metodologia adotada visa revelar hipóteses e variáveis que podem compor um questionário para aplicação em uma amostra significativa dos usuários de cursos EaD em São Paulo ou mesmo outras praças em uma pesquisa aprofundada futuramente. Por ora, pode apontar essas tendências e dificuldades atuais da fruição do ensino EaD.

\section{Paisagens sonoras na construção do ambiente de aprendizagem}

Dayana Islas é administradora, pós-graduada e estuda inglês na modalidade semipresencial, tendo 1 hora de aula presencial por semana "na hora do almoço" de seu trabalho e estudando o material didático "durante o percurso entre casa e trabalho, no transporte público", totalizando $2 \mathrm{~h} 30$ de estudo, por dia, de material EaD, no trem e metrô. Ela comenta que a maior dificuldade é quando o transporte público está lotado, pois alguém pode esbarrar nela e tirar sua concentração, mas acredita que, no geral, é possível estudar nessas condições, pois "quando chego em casa, meu tempo é curto e preciso ainda dormir, tomar banho, arrumar roupa para o dia seguinte, entre outras atividades", diz Dayana. 
A rotina intensa de trabalho e a incompatibilidade de agenda com o horário de cursos presenciais são fatores de grande influência na busca por cursos na modalidade EaD. Roberta Iahn é professora universitária e utiliza transporte público para ir ao trabalho. Ela é professora universitária e aluna de cursos de extensão na modalidade EaD e pretende ingressar em uma nova formação em bacharelado nesta modalidade. Entrevistada, ela disse que "trabalha no horário em que poderia estudar. Cursos presenciais são muito limitados para o meu perfil. Pensei em estudar EaD para não deixar de estudar o que desejo." Ela fez cursos em EaD estudando de madrugada, aos finais de semana, ou mesmo em trânsito. "Eu leio muito em qualquer lugar". Roberta relata que enjoa ao ler em veículos automotivos, mas que se adapta bem à leitura no metrô. Ficou muito satisfeita ao trocar os livros pelo Kindle (plataforma que abriga publicações digitalizadas). Assim como Dayana, ocupa seus tempos de ócio (madrugada, fim de semana e deslocamento) com o estudo de um conteúdo midiatizado.

O professor e radialista Sérgio Pinheiro cursa uma licenciatura na modalidade EaD, “aproveitando o tempo que perde no transporte público em São Paulo", lendo textos enquanto se desloca e assistindo vídeos em casa quando tem algum tempo livre. "Quanto aos estudos para a prova e os trabalhos, procuro encontrar algum tempo na correria do dia a dia", diz. Sérgio estuda no trem e metrô, especialmente no trem, cujo trajeto que percorre é mais longo; ele aponta dificuldade para concentração, porque "as pessoas conversam alto, outras ligam música". Apesar das dificuldades da fruição, ele acredita que a modalidade seja um método válido de aprendizagem e não percebe o convívio com outros alunos como um fator indispensável ou motivador; para ele, poderia até atrapalhá-lo em uma modalidade de ensino presencial. "O pró acho que é exatamente aproveitar um tempo perdido. O contra é a dificuldade de concentração e acho que o estudo apostilado não chega nem perto do contato próximo na sala de aula. Acho que os cursos EAD são mais interessantes para quem já tem uma vivência e não teria mais paciência de estar em uma sala com jovens em outro ritmo de vida."

Em comum, todos entrevistados são pós-graduados e atuantes no mercado, possuem uma rotina de trabalho intensa, utilizam transporte público para se deslocar da casa ao trabalho e possuem interesse em seguir estudando e se especializando, embora não consigam conciliar tempo (e distâncias) para estudar presencialmente. Sérgio ainda apontou a convivência com pessoas mais jovens, que estariam em sua primeira formação e "em outro ritmo de vida" como um estímulo negativo ao ensino presencial.

As entrevistas revelam a hipótese de que a principal vantagem da midiatização da educação pode ser o "ritmo" do aprendizado pelo aluno. O estudo na modalidade EaD acontece 
nas temporalidades e espacialidades que o aluno deseja realizar o consumo midiático do material didático; ele pode estudar em sua casa, no trabalho ou mesmo ocupar seus tempos ociosos com a atividade do estudo. $\mathrm{O}$ estudo midiatizado é customizado às necessidades, inclusive de tempo, espaços e mediações, de seus usuários, que escolhe as temporalidades e espacialidades que considerarem adequados à prática da atividade. A concentração do aluno acontece quando ele realiza a imersão na paisagem sonora do conteúdo midiatizado do EaD.

Em sua entrevista, Sérgio Pinheiro falou da dificuldade em estudar durante o deslocamento num coletivo devido às conversas em som alto e músicas ouvidas pelos outros usuários do transporte público e concluiu: "Mas quando o assunto é interessante a concentração se torna maior, então também depende do tema". Entrevistas revelam opiniões subjetivas, como a de Sérgio: é subjetivo definir o que torna um tema interessante ou atribuir a ele a capacidade de reter a concentração de um aluno. Porém, é fato, conforme Schafer (2001), que a fruição de um conteúdo pode promover a imersão de seu receptor na paisagem sonora criada por esses sons.

O conceito de Schafer define uma composição ambiental a partir do som, uma construção de imaginários e outros estímulos sensoriais a partir da audição de sons que evocam memórias e conhecimentos. Aplicado à midiatização da educação, é possível conceber a construção de um ambiente que remeta a uma instituição de ensino a partir de uma paisagem sonora formada, essencialmente, pelo material didático midiatizado disponibilizado aos alunos, seja em formatos sonoros, como podcasts, seja em formatos audiovisuais como vídeos de aulas.

A partir dessa lógica, a "espacialidade", o ambiente educacional, acompanha o aluno por onde estiver; o aluno em deslocamento leva consigo, em seu imaginário, uma paisagem sonora que lhe ambienta em um "lugar" da educação entre seu local de trabalho e sua residência, competindo com a paisagem sonora do ambiente do meio de transporte. O aluno cria sua paisagem sonora customizada que compete com os sons do mundo presentes nessas espacialidades.

\footnotetext{
O exercício do ócio de ouvir não tem lugar em nossa sociedade, pois vivemos sob o código da velocidade e das conexões. Valorizamos nossas conquistas, nossa imagem e não nossas relações. Quando acordamos cedo e pegamos o Metrô para o trabalho, estamos com nossos sentidos fechados às experiências, os ouvidos tampados ao ambiente ao nosso redor. Resta-nos a fixação pelas imagens e a fluidez das informações. Corremos para vencer, mas na verdade vamos em direção à imagem da vitória. Construímos uma "segunda realidade" desafiadora na competitividade, como uma manifestação do lúdico. Desta forma, nos aprisionamos nos códigos que nós mesmos criamos, reféns da "vitória" e esquecidos nas relações. (FERNANDES, 2010, p. 81-82).
} 
Quando Fernandes (2010) menciona o ócio do ouvir, evoca o ócio citado por De Masi (2000), da reflexão, contemplação e criatividade. Para Fernandes (2010), o consumo midiático dessas mediações tecnológicas, como conteúdos digitais, em deslocamento inibe o "ócio do ouvir".

\begin{abstract}
As mediações secundárias ${ }^{2}$ foram capazes de nos separar do tempo presente, possibilitando um tempo de reflexão, de memória [...]. Já as mediações terciárias promovem uma redução no espaço, ou mesmo sua anulação, com a condição de que ambos os lados da comunicação tenham acesso a aparatos de codificação e decodificação. As mediações terciárias suprimem o tempo lento e resgatam a oralidade, porém esta hipertrofiada pela velocidade nas conexões, em um tempo que, na verdade, é uma ilusão do presente, uma ilusão de proximidade. Movemo-nos com extrema velocidade e somos capazes de escolhermos as conexões que desejamos. Assim, perdem-se os conceitos de união, engajamento, ou parentesco, e fica o conceito de "rede". (FERNANDES, 2010, p. 82).
\end{abstract}

Em seu estudo, Fernandes (2010) distingue a fruição de uma mediação secundária, como um livro ou jornal, que, em sua perspectiva possibilitam "um tempo de reflexão, de memória", do consumo midiático de uma mediação terciária, como a interação com ambientes digitais proporcionadas por tablets e smartphones, as principais plataformas para acesso a material didático midiatizado. Sob sua perspectiva, o potencial de reprodução da realidade por meio de conteúdos audiovisuais reproduz também o tempo acelerado da sociedade do cansaço, da busca pelo desempenho e pelo sucesso. Dessa forma, a paisagem sonora capaz de criar um ambiente de educação pode também criar um ambiente de velocidade e competitividade que caracteriza a sociedade do cansaço.

Sob essa perspectiva, a criação de uma paisagem sonora adequada para ambientar uma localidade da prática da educação possuiria a linguagem e o ritmo lento necessário ao desfrute de uma instituição de ensino, com o acesso a todo seu material didático e interação com as pessoas que a fazem um local de troca e aprendizagem. Ainda assim, essa paisagem competiria com estímulos externos presentes nas localidades nas quais o exercício da prática do EaD seria realizado: a dificuldade de se sentir em um ambiente de educação enquanto ocupa o espaço de um não-lugar muito ocupado e ruidoso.

\title{
Reflexões sobre a midiatização da educação
}

O processo de midiatização pelo qual passa o campo da educação é transmidiático e acontece há algumas décadas, desde o estudo por apostilas enviadas pelos Correios, ao advento

\footnotetext{
${ }^{2}$ Os conceitos de mediações primárias, secundárias e terciárias se aplicam às mediações que envolvem as mídias primárias, secundárias e terciárias conforme termos cunhados por Harry Pross, em sua Teoria das Mídias. Assim, as mediações primárias são mediadas pelo corpo, as secundárias por um suporte tecnológico que permite a transmissão de conteúdos como livros, revistas e televisão e, o terciário permite a circulação da comunicação entre emissor e receptor, como por uso de mídias digitais.
} 
dos telecursos que eram transmitidos pelos canais de televisão até o relativamente recente surgimento dos cursos $\mathrm{EaD}$, estruturados sobre a produção e veiculação de material didático midiatizado em formato de textos, apostilas, podcasts e videoaulas. $\mathrm{O}$ crescimento da demanda por essa modalidade de ensino denota uma aceitação desse formato, adequado ao ritmo e necessidade de educação em localidades e temporalidades escolhidas por seus alunos de forma que não se conflitem com os tempos e locais de outras práticas socioculturais. A organização e planejamento para consumo midiático das aulas $\mathrm{EaD}$ são de responsabilidade de cada aluno, que tem de responder aos exercícios nos prazos determinados pelos propositores (e produtores e distribuidores) dos cursos.

Assim, esse fenômeno pode ser percebido como um processo com grandes potencialidades, permitindo que pessoas sem condições de cursar um ensino presencial, por quaisquer que sejam seus motivos (financeiros, não possuir acesso a instituição de ensino, não possuir tempo para assistir às aulas presenciais nos horários em que são ofertadas) seguir estudando nas espacialidades e temporalidades que lhes for possível.

Aproximando esses dispositivos educacionais da realidade vivida em grandes centros urbanos, como na metrópole de São Paulo, suas potencialidades são ainda mais valorizadas, uma vez que o tempo das atividades realizadas no cotidiano competem com o tempo de deslocamento entre as espacialidades que ambientam essas práticas, de forma que um cidadão de um centro urbano possui dificuldade em organizar seu tempo de forma a praticar aulas presencialmente em institutos de educação. Nesse cenário, o EaD apresenta-se como uma ferramenta bastante acessível para que o cidadão tenha acesso a materiais didáticos nas espacialidades e temporalidades de seus "tempos mortos", aí incluso os longos períodos de deslocamento entre as localidades que organizam seu cotidiano, como sua residência e seu local de trabalho.

Faz-se necessário, apenas, refletir sobre as temporalidades impostas pela "sociedade do cansaço", pautada sobre a performance, o desempenho, busca incessante pelo sucesso e luta contra o desperdício de "tempos mortos". Cabe-nos lembrar que o tempo do ócio é necessário ao descanso, criatividade e renovação da disposição, assim como à reflexão e ao pensamento analítico. "Pura inquietação não gera nada de novo. Reproduz e acelera o já existente" (HAN, 2017, p. 34). O campo da educação é local do pensamento e produção de conhecimento, atividades que não se realizam plenamente em ambientes de pressa e interrupções frequentes. 


\section{Referências}

AUGÉ, Marc. Não-lugares: introdução a uma antropologia da supermodernidade. Campinas: Papirus, 2004.

DE MASI, Domenico. O ócio criativo. Rio de Janeiro: Sextante, 2000.

FERNANDES, Rodrigo Fonseca. Jogos orquestrais: vínculos sonoros nas jornadas esportivas da Eldorado/ESPN. 2010. 142 f. Dissertação (Mestrado em Comunicação na Contemporaneidade) - Programa em Comunicação na Contemporaneidade, Faculdade Cásper Líbero, São Paulo, 2010.

HAN, Byung-Chul. Sociedade do cansaço. Petrópolis: Vozes, 2017.

HEPP, Andreas. As configurações comunicativas de mundos midiatizados: pesquisa da midiatização na era da "mediação de tudo". Matrizes, São Paulo, v. 8, n.1, p. 45-64, jan./jun. 2014.

HEPP, Andreas. Mediatization, media technologies and the moulding forces of the media. In: International Communication Association Annual Conference, 2011, Boston, EUA, p.1-23, Anais... Boston, EUA, 2011. Disponível em: <www.andreashepp.name/Blog/Eintrage/2011/5/26_Paper_auf_der_ICA.Tagung_und_mehr_ fies/Hepp.pdf>. Acesso em: 30 nov. 2017.

HJARVARD, Stig. Midiatização: conceituando a mudança social e cultural. Matrizes, São Paulo, v. 8, n. 1, p. 21-44, jan./jun. 2014. Disponível em: < http://www.matrizes.usp.br/index.php/matrizes/article/view/560/pdf >. Acesso em: 10 nov. 2017.

HJARVARD, Stig. Midiatização: teorizando a mídia como agente de mudança social e cultural. Matrizes, São Paulo, v. 5, n. 2. p. 53-92, jan./jun. 2012. Disponível em:

<http://www.matrizes.usp.br/index.php/matrizes/article/view/338/pdf >. Acesso em: 10 nov. 2017.

LOPES, Maria Immacolata V. de. Mediação e recepção. Algumas conexões teóricas e metodológicas nos estudos latino-americanos de comunicação. Matrizes, São Paulo, v. 8, n. 1. p. 21-44, jan./jun. 2014. Disponível em:

<www.matrizes.usp.br/index.php/matrizes/article/download/564/pdf>. Acesso em: 10 nov. 2017.

MARTÍN-BARBERO, Jesús. Dos meios às mediações: comunicação, cultura e hegemonia. Rio de Janeiro: UFRJ, 2008.

MARTÍN-BARBERO, Jesús. Ofício de cartógrafo. Travessias latino-americanas da comunicação na cultura. São Paulo: Loyola, 2004.

SCHAFER, Murray. A afinação do mundo. São Paulo: Unesp, 2001.

Eric de Carvalho - Faculdade Cáper Libero | São Paulo-SP | Brasil. E-mail: ericdecarvalho1@gmail.com. 